\title{
CARACTERÍSTICAS DO TIPO DE ALIMENTAÇÃO E DA FALA DE CRIANÇAS COM E SEM APINHAMENTO DENTÁRIO
}

\section{Characteristics of food consistence and speech production in children with normal occlusion and malocclusion related to tooth crowding}

\author{
Cláudia Ribeiro Pena (1), Mônica Medeiros de Britto Pereira ${ }^{(2)}$, \\ Esther Mandelbaum Gonçalves Bianchini ${ }^{(3)}$
}

\begin{abstract}
RESUMO
Objetivo: caracterizar o tipo de consistência alimentar e a articulação da fala em crianças com oclusão normal e com apinhamento dentário, verificando-se possíveis correlações e interferências. Métodos: participaram 60 crianças, de ambos os sexos, entre 7 e 12 anos, divididas em dois grupos. G1: 30 crianças com apinhamento dentário, G2: 30 crianças sem apinhamento dentário, conforme avaliação odontológica. Foram critérios de exclusão: déficits neurológicos e cognitivos, presença de hábitos orais, respiração oral crônica, deformações dentofaciais, realização de tratamento ortopédico/ortodôntico e/ou fonoaudiológico. Foram realizadas: avaliação do sistema estomatognático; avaliação odontológica quanto à situação dento-oclusal; aplicação de questionários aos pais visando contemplar critérios de exclusão e definir os hábitos alimentares quanto à sua consistência; avaliação de fala quanto à produção fonética e fonológica. Resultados: crianças sem apinhamento dentário têm alimentação predominantemente dura, enquanto aquelas com apinhamento dentário têm alimentação predominantemente amolecida; caracterizada principalmente pelo hábito de ingestão de líquido na presença do alimento na boca. Quanto à fala, não foram encontradas alterações significativas independente do apinhamento dentário e do tipo de consistência alimentar. Conclusão: há indícios de que a presença do apinhamento dentário relaciona-se à consistência alimentar. A alimentação amolecida parece constituir provável fator etiológico ou contribuinte à existência do apinhamento dentário. $\mathrm{O}$ tipo de alimentação e a presença de apinhamento dentário parecem não interferir na articulação da fala.
\end{abstract}

DESCRITORES: Oclusão Dentária; Má Oclusão; Criança; Fala; Distúrbios da Fala; Transtornos da Articulação

\section{INTRODUÇÃO}

Verificando-se o desenvolvimento do ser humano, percebem-se grandes modificações de suas características anátomo-fisiológicas durante sua evolução. Estudos antropológicos demonstram que a cabeça do homem sofreu modificações e,

(1) Fonoaudióloga; Mestre em Fonoaudiologia pela Universidade Veiga de Almeida - RJ.

(2) Fonoaudióloga; Coordenadora do Mestrado Profissional em Fonoaudiologia da Universidade Veiga de Almeida RJ; Doutora em Lingüística pela Universidade Federal de Minas Gerais.

(3) Fonoaudióloga; Professora Adjunta do Mestrado Profissional em Fonoaudiologia da Universidade Veiga de Almeida RJ; Doutora em Ciências Fisiopatologia Experimental pela Faculdade de Medicina da Universidade de São Paulo. em especial o sistema estomatognático, provavelmente em conseqüência da mudança de seus hábitos comportamentais e alimentares, pois o homem primitivo utilizava seu sistema mastigatório intensamente, não só pela variação do tipo de alimento, mas também como ferramenta ou arma de ataque e defesa em suas lutas ${ }^{1-3}$. Isso o difere do homem moderno, pós-revolução industrial, que ingere alimentos mais amolecidos e que passam por fases prévias de preparação. A consistência da alimentação atual é bem diferente, podendo minimizar, a cada dia, a ação da mastigação e assim provocar crescente modificação anátomo-fisiológica, aumentando as possibilidades de perturbações em todo o sistema ${ }^{3,4}$.

Os alimentos duros parecem exercer influência em diversas estruturas, tal como a força da muscu- 
latura oral aumentando a carga de função sobre os dentes, atuando não apenas na qualidade da mastigação como também no desenvolvimento e manutenção dos ossos maxilares, dos arcos dentários e de todo sistema estomatognático, possibilitando assim menores interferências oclusais ${ }^{1,2,4-6}$. Já os alimentos moles teriam efeito atrófico sobre os ossos maxilares contribuindo para o aparecimento de má oclusão ${ }^{2,7,8}$.

Tais considerações não são unânimes na literatura, pois estudos envolvendo população préhistórica e de séculos anteriores encontraram má oclusão e apinhamentos ${ }^{9-11}$, divergindo de estudos os quais referem que eram raras nessas populações ${ }^{1-4}$. Concluem que tais alterações têm origem genética e não são causadas apenas por tamanho do dente ou por mudanças em fatores ambientais e mudanças da função mastigatória 9-11.

Para testar a hipótese de que os fatores ambientais; tais como a introdução de alimentos refinados e processados nas dietas alimentares, são significantes na oclusão e no desenvolvimento craniofacial provocando aumento rápido da prevalência de má oclusão na população; foram realizadas pesquisas experimentais em animais: miniporcos ${ }^{7}$, furões ${ }^{8} \mathrm{e}$ ratos ${ }^{12-14}$. Os resultados mostram que, em todos os tipos de animais pesquisados, evidenciam-se diferenças significativas de crescimento entre os grupos comparados, sendo que nos grupos com dieta macia ocorreu crescimento reduzido em diversas estruturas craniofaciais, quando comparados aos grupos com dieta dura. Pontuam que existe uma relação entre a consistência alimentar e a oclusão e que esta mudança na consistência alimentar influencia a morfologia craniofacial ao mudar a demanda funcional dos músculos mastigatórios 1,7,8,12-15.

$\mathrm{Na}$ clínica odontológica, a falta de espaço para a acomodação dos dentes alinhados nas arcadas dentárias é denominada apinhamento dentário, ou seja, discrepância entre a largura dos dentes e o espaço disponível no processo alveolar ${ }^{9-11}$. Trata-se de alteração ortodôntica relatada como a de maior prevalência nas populações estudadas ${ }^{16-18}$. Entretanto a literatura aponta que não se refere apenas à discrepância de tamanho entre dentes e arcos, pois uma vez que se trata de problema de etiologia multifatorial, muitas variáveis como direção de crescimento mandibular, perda precoce dos dentes decíduos, ação da musculatura oral, peri-oral e mastigatória e inclinação dos dentes podem estar associadas com o apinhamento 9-11,16-19.

A oclusão normal ou compensada é condição essencial para que os dentes realizem a função mastigatória, além de influir na precisão e qualidade articulatória dos sons ${ }^{20-22}$. Os alimentos secos, duros e fibrosos são considerados importantes para o desenvolvimento do sistema estomatognático por provocarem forte estímulo durante o treino mastigatório e a maturação dessas funções ${ }^{5,23}$, pois crianças que só se alimentam de alimentos macios podem apresentar problemas articulatórios devido a hipotonia funcional dos músculos faciais ${ }^{20,22}$.

As distorções dos sons da fala podem associarse às alterações nas estruturas dentárias e à má oclusão ${ }^{24-27}$, uma vez que essas são relatadas como fatores etiológicos das distorções fonéticas ${ }^{22,28,}$ tendo como fonemas mais afetados os linguodentais, alveolares e labiodentais ${ }^{24}$. Entretanto, alguns autores ${ }^{29}$, após pesquisarem 132 crianças, verificaram que a presença da alteração oclusal pode ser um fator de risco para o desenvolvimento do ceceio anterior na fala, mas não é determinante para a sua ocorrência. Em contrapartida, estudo com alterações oclusais incluindo apinhamento dentário refere que as distorções na fala não estão relacionadas com a oclusão ${ }^{30}$.

A preocupação dos profissionais envolvidos nesse campo deve voltar-se não apenas às técnicas de tratamento quando o problema já se encontra instalado, mas também à compreensão dos fatores etiológicos que possam originar ou agravar tais alterações funcionais e/ou estéticas. Questiona-se assim se a falta de mastigação eficiente devido à utilização de alimentação amolecida, deixaria de transmitir estímulos favoráveis de crescimento e de organização da posição dos dentes, colaborando com a ocorrência de apinhamento dentário, assim como interferindo na articulação dos sons da fala. Como a literatura mostra opiniões variadas, este trabalho teve como objetivos: caracterizar o tipo de alimentação e a produção da fala de crianças com e sem apinhamento dentário buscando analisar possíveis relações entre a presença de apinhamento e o tipo de alimentação, assim como associar a produção da fala, quanto à presença ou não de alterações fonéticas e fonológicas, com o tipo de alimentação e presença de apinhamento dentário.

\section{MÉTODOS}

Esta pesquisa foi realizada na cidade do Rio de Janeiro, na clínica de odontologia da Universidade Veiga de Almeida, após processos éticos pertinentes e assinatura do Termo de Consentimento Livre e Esclarecido pelos responsáveis.

Fizeram parte desse estudo 60 crianças apresentando dentição mista, na faixa etária entre 7 anos e 12 anos e 10 meses, ambos os sexos, divididas em dois grupos balanceados quanto à faixa etária e quanto ao sexo:

- G1: 30 crianças com apinhamento dentário

- G2: 30 crianças sem apinhamento dentário 
Todas as crianças encontravam-se em avaliação nos setores de odontopediatria e ortodontia da Clínica de Odontologia da Universidade Veiga de Almeida e foram diagnosticadas quanto à presença ou ausência de apinhamento dentário no curso de especialização em ortodontia pelo odontólogo responsável, num período de 8 meses.

Foram critérios de exclusão: déficits neurológicos e cognitivos, falhas dentárias precoces posteriores, presença de hábitos orais, sinais de respiração oral crônica, deformações dentofaciais e estruturais do sistema estomatognático, realização de tratamento ortopédico/ortodôntico e/ou fonoaudiológico; uma vez que estas características poderiam interferir na caracterização do espaço dos arcos dentários e na produção articulatória da fala.

A verificação de tais critérios foi realizada por meio de avaliação de seleção, aplicação de ques- tionário aos pais referentes ao histórico da criança e avaliação clínica por meio de observação direta nos órgãos fonoarticulatórios realizada pela pesquisadora (Figura 1).

Para definição do tipo de alimentação quanto à consistência foi aplicado aos pais, por meio de entrevista com a pesquisadora, um questionário contendo perguntas fechadas referente aos hábitos alimentares de seus filhos (Figura 2). Para a elaboração desse instrumento criado para essa pesquisa, foram verificados trabalhos anteriores que apresentassem classificação do tipo de alimentação ${ }^{23,26}$, definidas as perguntas e opções de respostas quanto ao tipo de alimento considerando-se sua consistência, e posterior caracterização do tipo de consistência por meio de estudo estatístico. Para verificação da clareza, da eficiência das perguntas e classificação de respostas foi realizado estudo piloto ${ }^{31}$.
Nome:
Data de Nascimento:
Alterações dentofaciais:
( ) Sim
( ) Não
Alteração nas estruturas do SE:
( ) Sim
( ) Não
Alteração neurológica:
( ) Sim
( ) Não
Fez ou faz tratamento fonoaudiológico:
( ) Sim
( ) Não
Faz uso de aparelho ortodôntico:
( ) Sim
( ) Não
Hábito oral deletério:
( ) Sim
( ) Não
Sinais de Respiração oral crônica:
( ) Sim
( ) Não
Apinhamento Dentário:
( ) Presente
( ) Ausente

Idade:

Gênero:

Figura 1 - Protocolo de Avaliação de Seleção

Nome:

1. Seu filho come carne em bife?

( ) Sim, mais que 3 vezes na semana

Data de Nascimento:

Idade:

Gênero:

( ) Não, apenas uma vez na semana ou menos

2. Ele tem dificuldade para mastigar o bife?
( ) Sim
( ) Não ou raramente

Tem que partir o bife pequeno?
( ) Sim

4. Coloca muito feijão na comida?

( ) Sim

5. Durante a refeição, ingere o líquido?

( ) Sim, ainda com o alimento na boca ( ) Não ou somente após engolir o alimento

6.Come frutas com casca, tais como maçã ou pêra?
( ) Sim
( ) Não ou raramente

7. Tem dificuldade ou preguiça para comer alimentos mais duros?
( ) Sim
( ) Não

8. Come pão de sal completo?

( ) Sim, mais que 3 vezes na semana

( ) Não, apenas uma vez na semana ou menos 


\begin{tabular}{|c|c|c|c|c|c|c|c|c|}
\hline & $\begin{array}{l}\text { árvore } \\
\text { evocação [ ] }\end{array}$ & imitação [ ] & & $\begin{array}{l}\text { diabo } \\
\text { evocação [ ] }\end{array}$ & imitação [ ] & 53. & $\begin{array}{l}\text { nariz } \\
\text { evocação [ ] }\end{array}$ & imitação [ ] \\
\hline 2. & $\begin{array}{l}\text { atleta } \\
\text { evocação [ ] }\end{array}$ & imitação [ ] & 28. & $\begin{array}{l}\text { dragão } \\
\text { evocação [ ] }\end{array}$ & imitação [ ] & 54. & $\begin{array}{l}\text { noiva } \\
\text { evocação [ ] }\end{array}$ & imitação [ ] \\
\hline 3. & $\begin{array}{l}\text { avião } \\
\text { evocação [ ] }\end{array}$ & imitação [ ] & 29. & $\begin{array}{l}\text { elefante } \\
\text { evocação [ ] }\end{array}$ & imitação [ ] & 55. & $\begin{array}{l}\text { Olho } \\
\text { evocação [ ] }\end{array}$ & imitação | \\
\hline 4. & $\begin{array}{l}\text { banana } \\
\text { evocação [ ] }\end{array}$ & imitação [ ] & 30. & $\begin{array}{l}\text { estrela } \\
\text { evocação [ ] }\end{array}$ & imitação [ ] & 56. & $\begin{array}{l}\text { ônibus } \\
\text { evocação [ ] }\end{array}$ & imitação [ ] \\
\hline 5. & $\begin{array}{l}\text { barco } \\
\text { evocação [ ] }\end{array}$ & imitação [ ] & 31. & $\begin{array}{l}\text { explosão } \\
\text { evocação [ ] }\end{array}$ & imitação [ ] & 57. & $\begin{array}{l}\text { palhaço } \\
\text { evocação [ ] }\end{array}$ & imitação [ ] \\
\hline 6. & $\begin{array}{l}\text { bicicleta } \\
\text { evocação [ ] }\end{array}$ & imitação [ ] & 32. & $\begin{array}{l}\text { flauta } \\
\text { evocação [ ] }\end{array}$ & imitação [ ] & 58. & $\begin{array}{l}\text { passarinho } \\
\text { evocação [ ] }\end{array}$ & imitação \\
\hline 7. & $\begin{array}{l}\text { bloco } \\
\text { evocação [ ] }\end{array}$ & imitação [ ] & 33. & $\begin{array}{l}\text { flor } \\
\text { evocação [ ] }\end{array}$ & imitação [ ] & 59. & $\begin{array}{l}\text { pedra } \\
\text { evocação [ ] }\end{array}$ & imitação \\
\hline 8. & $\begin{array}{l}\text { bola } \\
\text { evocação [ ] }\end{array}$ & imitação [ ] & 34. & $\begin{array}{l}\text { fogão } \\
\text { evocação [ ] }\end{array}$ & imitação [ ] & 60. & $\begin{array}{l}\text { peixe } \\
\text { evocação [ ] }\end{array}$ & imitação [ ] \\
\hline 9. & $\begin{array}{l}\text { bolsa } \\
\text { evocação [ ] }\end{array}$ & imitação [ ] & 35. & $\begin{array}{l}\text { fralda } \\
\text { evocação [ ] }\end{array}$ & imitação [ ] & 61. & $\begin{array}{l}\text { placa } \\
\text { evocação [ ] }\end{array}$ & imitação [ ] \\
\hline 10. & $\begin{array}{l}\text { borboleta } \\
\text { evocação [ ] }\end{array}$ & imitação [ ] & 36. & $\begin{array}{l}\text { garfo } \\
\text { evocação [ ] }\end{array}$ & imitação [ ] & 62. & $\begin{array}{l}\text { prato } \\
\text { evocação [ ] }\end{array}$ & imitação \\
\hline 11. & $\begin{array}{l}\text { braço } \\
\text { evocação [ ] }\end{array}$ & imitação [ ] & 37. & $\begin{array}{l}\text { garrafa } \\
\text { evocação [ ] }\end{array}$ & imitação [ ] & 63. & $\begin{array}{l}\text { presente } \\
\text { evocação [ ] }\end{array}$ & imitação [ ] \\
\hline 12. & $\begin{array}{l}\text { brigadeiro } \\
\text { evocação [ ] }\end{array}$ & imitação [ ] & 38. & $\begin{array}{l}\text { gato } \\
\text { evocação [ ] }\end{array}$ & imitação [ ] & 57. & $\begin{array}{l}\text { quadrado } \\
\text { evocação [ ] }\end{array}$ & imitação [ ] \\
\hline 13. & $\begin{array}{l}\text { bruxa } \\
\text { evocação [ ] }\end{array}$ & imitação [ ] & 39. & $\begin{array}{l}\text { girafa } \\
\text { evocação [ ] }\end{array}$ & imitação [ ] & 65. & $\begin{array}{l}\text { quadro } \\
\text { evocação [ ] }\end{array}$ & imitação \\
\hline 14. & $\begin{array}{l}\text { cachorro } \\
\text { evocação [ ] }\end{array}$ & imitação [ ] & 40. & $\begin{array}{l}\text { globo } \\
\text { evocação [ ] }\end{array}$ & imitação [ ] & 66. & $\begin{array}{l}\text { rato } \\
\text { evocação [ ] }\end{array}$ & imitação [ \\
\hline 15. & $\begin{array}{l}\text { cadeira } \\
\text { evocação [ ] }\end{array}$ & imitação [ ] & 41. & $\begin{array}{l}\text { gravata } \\
\text { evocação [ ] }\end{array}$ & imitação [ ] & 67. & $\begin{array}{l}\text { régua } \\
\text { evocação [ ] }\end{array}$ & imitação [ \\
\hline 16. & $\begin{array}{l}\text { caminhão } \\
\text { evocação [ ] }\end{array}$ & imitação [ ] & 42. & $\begin{array}{l}\text { guarda - chuva } \\
\text { evocação [ ] }\end{array}$ & imitação [ ] & 68. & $\begin{array}{l}\text { relógio } \\
\text { evocaçãão [ ] }\end{array}$ & imitação \\
\hline 17. & $\begin{array}{l}\text { carro } \\
\text { evocação [ ] }\end{array}$ & imitação [ ] & 43. & $\begin{array}{l}\text { igreja } \\
\text { evocação [ ] }\end{array}$ & imitação [ ] & 69. & $\begin{array}{l}\text { sapato } \\
\text { evocação [ ] }\end{array}$ & imitação \\
\hline 18. & $\begin{array}{l}\text { chupeta } \\
\text { evocação [ ] }\end{array}$ & imitação [ ] & 44. & $\begin{array}{l}\text { janela } \\
\text { evocação [ ] }\end{array}$ & imitação [ ] & 70. & $\begin{array}{l}\text { sorvete } \\
\text { evocação [ ] }\end{array}$ & imitação [ ] \\
\hline 19. & $\begin{array}{l}\text { classe } \\
\text { evocação [ ] }\end{array}$ & imitação [ ] & 45. & $\begin{array}{l}\text { lápis } \\
\text { evocação [ ] }\end{array}$ & imitação [ ] & 71. & $\begin{array}{l}\text { tartaruga } \\
\text { evocaç̧ão [ ] }\end{array}$ & imitação \\
\hline 20. & $\begin{array}{l}\text { cobra } \\
\text { evocação [ ] }\end{array}$ & imitação [ ] & 46. & $\begin{array}{l}\text { livro } \\
\text { evocação [ ] }\end{array}$ & imitação [ ] & 72. & $\begin{array}{l}\text { telefone } \\
\text { evocação [ ] }\end{array}$ & imitação [ ] \\
\hline 21. & $\begin{array}{l}\text { coelho } \\
\text { evocação [ ] }\end{array}$ & imitação [ ] & 47. & $\begin{array}{l}\text { luva } \\
\text { evocação [ ] }\end{array}$ & imitação [ ] & 74. & $\begin{array}{l}\text { trem } \\
\text { evocação [ ] }\end{array}$ & imitação [ ] \\
\hline 22. & $\begin{array}{l}\text { lofre } \\
\text { evocação [ ] }\end{array}$ & imitação [ ] & 48. & $\begin{array}{l}\text { macaco } \\
\text { evocação [ ] }\end{array}$ & imitação [ ] & 75. & $\begin{array}{l}\text { três } \\
\text { evocaç̧ão [ ] }\end{array}$ & imitação | \\
\hline 23. & $\begin{array}{l}\text { comprido } \\
\text { evocação [ ] }\end{array}$ & imitação [ ] & 49. & $\begin{array}{l}\text { maçã } \\
\text { evocação [ ] }\end{array}$ & imitação [ ] & 16. & $\begin{array}{l}\text { ventilador } \\
\text { evocaç̧ão [ ] }\end{array}$ & imitação [ ] \\
\hline 24. & $\begin{array}{l}\text { criança } \\
\text { evocação [ ] }\end{array}$ & imitação [ ] & 50 & $\begin{array}{l}\text { mesa } \\
\text { evocação [ ] }\end{array}$ & imitação [ ] & 17. & $\begin{array}{l}\text { verde } \\
\text { evocação [ ] }\end{array}$ & imitação [ ] \\
\hline 25. & $\begin{array}{l}\text { cruz } \\
\text { evocação [ ] }\end{array}$ & imitação [ ] & 51. & $\begin{array}{l}\text { microfone } \\
\text { evocação [ ] }\end{array}$ & imitação [ ] & 18. & $\begin{array}{l}\text { xícara } \\
\text { evocaç̧ão [ ] }\end{array}$ & imitação [ ] \\
\hline 26. & $\begin{array}{l}\text { dedo } \\
\text { evocação [ ] }\end{array}$ & imitação [ ] & 52. & $\begin{array}{l}\text { mosquito } \\
\text { evocação [ ] }\end{array}$ & imitação [ ] & 79. & $\begin{array}{l}\text { zebra } \\
\text { evocação [ }\end{array}$ & imitação [ ] \\
\hline
\end{tabular}

Figura 3 - Protocolo de Avaliação de Fala - UVA 
Para tabulação dos dados e posterior tratamento estatístico quanto aos hábitos alimentares que pudessem caracterizar o tipo de alimentação, foram necessários os seguintes critérios:

- classificação da alimentação em: amolecida, equilibrada ou dura

- as perguntas foram divididas em grupo A (perguntas 1, 6 e 8) e grupo B (perguntas 2, 3, 4, 5 e 7)

- para caracterizar a alimentação como dura foram consideradas as respostas afirmativas referentes às perguntas do grupo $A$ e as respostas negativas relativas às perguntas do grupo $B$, com porcentagem superior a $50 \%$ em relação ao total de respostas obtidas.

- para caracterizar alimentação como amolecida foram consideradas as respostas negativas referentes às perguntas do grupo $A$ e as respostas afirmativas relativas às perguntas do grupo B, com porcentagem superior a $50 \%$ em relação ao total de respostas obtidas.

- para caracterizar a alimentação como equilibrada foram consideradas as respostas afirmativas referentes às perguntas do grupo $\mathrm{A}$ e as respostas negativas relativas às perguntas do grupo $\mathrm{B}$, com porcentagem igual a $50 \%$ em relação ao total de respostas obtidas.

Os participantes foram avaliados em relação à produção fonética e fonológica, por meio de teste de fala, (Figura 3) protocolado pela Clínica de Fonoaudiologia da Instituição, constando de 79 figuras com corpus balanceado, aplicado pela pesquisadora. Para a coleta de amostra de fala, cada criança foi avaliada individualmente, e a fala gravada utilizando-se gravador digital Mini Disc Sony. Durante a aplicação da prova, foi realizada observação visual quanto à presença de interposição lingual e/ou labial na fala. As amostras foram analisadas verificando-se a ocorrência e incidência de adições, substituições, omissões, inversões, distorções de sons e imprecisão articulatória.

Este trabalho foi aprovado pela Comissão de Ética em Pesquisa da Universidade Veiga de Almeida sob o no 39/05.

A análise estatística foi realizada com o teste de Qui-quadrado indicado para verificar diferenças nas distribuições de uma característica em função de outra, no qual se mede o grau de relacionamento entre duas ou mais características categorizadas. Quando o valor calculado for maior ou igual ao valor crítico, diz-se que há diferença significativa, caso contrário, diz-se que não há diferença significativa. Os cálculos foram efetuados ao nível de significância de 0,05 (5\%). Todos os intervalos de confiança foram construídos com $95 \%$ de confiança estatística.

\section{RESULTADOS}

A Tabela 1 mostra a caracterização da amostra e distribuição dos participantes quanto ao sexo e quanto aos grupos em questão. A análise estatística mostra diferença estatisticamente não significante, confirmando que os grupos foram balanceados quanto a essa variável.

A Tabela 2 mostra a verificação das respostas do questionário quanto aos hábitos alimentares.

A partir das respostas obtidas por meio do questionário, foram tabulados os dados quanto ao tipo de alimentação referente à sua consistência. Utilizando-se os critérios adotados e anteriormente descritos para classificação da alimentação em dura, equilibrada e amolecida, foi realizada a distribuição dos participantes de acordo com o tipo de alimentação, para cada um dos grupos estudados, conforme se observa na Tabela 3. Pode-se observar que existe diferença significativa entre os dados, ou seja, maior porcentagem de crianças sem apinhamento dentário utiliza alimentação predominantemente dura, enquanto a maior porcentagem daquelas com apinhamento dentário prefere alimentação amolecida.

A Tabela 4 apresenta a distribuição dos participantes quanto aos resultados das características da fala quanto aos grupos estudados: com e sem apinhamento dentário. Pode-se observar que não há diferença significativa entre os dados, ou seja, a maior parte das crianças apresentou fala normal, independente de apinhamento dentário.

A Tabela 5 mostra a relação da fala com o tipo de alimentação de todos os participantes, independente do apinhamento dentário, na qual não são observadas diferenças estatisticamente significantes.

Tabela 1 - Distribuição freqüencial absoluta e relativa dos participantes de acordo com o sexo

\begin{tabular}{lccc}
\hline & Masculino & Feminino & Total \\
\cline { 2 - 4 } & $\mathbf{N}(\%)$ & $\mathbf{N}(\%)$ & $\mathbf{N}(\%)$ \\
\hline Com apinhamento & $13(43,33)$ & $17(56,67)$ & $30(100)$ \\
Sem apinhamento & $16(53,33)$ & $14(46,67)$ & $30(100)$ \\
\hline
\end{tabular}


Tabela 2 - Distribuição dos participantes com e sem apinhamento dentário conforme os hábitos alimentares

\begin{tabular}{ccccccc}
\hline Questões & \multicolumn{2}{c}{ G1: Com Apinhamento } & \multicolumn{2}{c}{ G2: Sem Apinhamento } & \multicolumn{2}{c}{ Estatística } \\
\hline & $\begin{array}{c}\text { Resposta } \\
\text { Sim }\end{array}$ & $\begin{array}{c}\text { Resposta } \\
\text { Não }\end{array}$ & $\begin{array}{c}\text { Resposta } \\
\text { Sim }\end{array}$ & $\begin{array}{c}\text { Resposta } \\
\text { Não }\end{array}$ & $\begin{array}{c}\text { Valor } \\
\text { Calculado }\end{array}$ & Valor Crítico \\
\cline { 2 - 5 } & $\begin{array}{c}\text { Participantes } \\
(\%)\end{array}$ & $\begin{array}{c}\text { Participantes } \\
(\%)\end{array}$ & $\begin{array}{c}\text { Participantes } \\
(\%)\end{array}$ & $\begin{array}{c}\text { Participantes } \\
(\%)\end{array}$ & & \\
\hline 1 & $8(26,67)$ & $22(73,33)$ & $17(56,67)$ & $13(43,33)$ & 4,39 & $3,84^{*}$ \\
2 & $19(63,33)$ & $11(36,67)$ & $8(26,67)$ & $22(73,33)$ & 6,73 & $3,84^{*}$ \\
3 & $17(56,67)$ & $13(43,33)$ & $13(43,33)$ & $17(56,67)$ & 0,6 & 3,84 \\
4 & $16(53,33)$ & $14(46,67)$ & $13(43,33)$ & $17(56,67)$ & 0,27 & 3,84 \\
5 & $25(83,33)$ & $5(16,67)$ & $6(20)$ & $24(80)$ & 21,64 & 3,84 * \\
6 & $14(46,67)$ & $16(53,33)$ & $19(63,33)$ & $11(36,67)$ & 1,08 & 3,84 \\
7 & $15(50)$ & $15(50)$ & $9(30)$ & $21(70)$ & 1,74 & 3,84 \\
8 & $29(96,67)$ & $1(3,33)$ & $28(93,33)$ & $2(6,67)$ & 0 & 3,84 \\
\hline
\end{tabular}

Tabela 3 - Distribuição freqüencial absoluta e relativa dos participantes de acordo com o tipo de alimentação

\begin{tabular}{ccccc}
\hline & Equilibrada & Dura & Amolecida & Total \\
\cline { 2 - 5 } & $\mathbf{N ~ ( \% )}$ & $\mathbf{N}(\%)$ & $\mathbf{N}(\%)$ & $\mathbf{N}(\%)$ \\
\hline Com apinhamento & $4(13,34)$ & $10(33,33)$ & $16(53,33)$ & $30(100)^{*}$ \\
Sem apinhamento & $5(16,67)$ & $23(76,66)$ & $2(6,67)$ & $30(100)^{*}$ \\
Total & $9(15,00)$ & $33(55,00)$ & $18(30,00)$ & $60(100) *$ \\
\hline
\end{tabular}

Tabela 4 - Distribuição freqüencial absoluta e relativa dos participantes de acordo com as características de fala para cada um dos grupos estudados

\begin{tabular}{ccccc}
\hline & Normal & Alteração fonética & $\begin{array}{c}\text { Alteração } \\
\text { fonológica }\end{array}$ & Total \\
\cline { 2 - 5 } & $\mathbf{N ~ ( \% )}$ & $\mathbf{N ~ ( \% )}$ & $\mathbf{N ~ ( \% )}$ & $\mathbf{N}(\%)$ \\
\hline Com apinhamento & $24(80,00)$ & $5(16,67)$ & $1(3,33)$ & $30(100)$ \\
Sem apinhamento & $18(60,00)$ & $10(33,33)$ & $2(6,67)$ & $30(100)$ \\
Total & 42 & 15 & 3 & $60(100)$ \\
\hline
\end{tabular}

Tabela 5 - Distribuição freqüencial absoluta e relativa quanto ao tipo de alimentação de todos os participantes, relacionada à produção da fala

\begin{tabular}{ccccc}
\hline \multirow{2}{*}{ Alimentação } & Fala Normal & Alteração Fonética & $\begin{array}{c}\text { Alteração } \\
\text { Fonológica }\end{array}$ & Total \\
\cline { 2 - 5 } & $\mathbf{N}(\%)$ & $\mathbf{N ~ ( \% )}$ & $\mathbf{N}(\%)$ & $\mathbf{N}(\%)$ \\
\hline Equilibrada & $6(67)$ & $2(22)$ & $1(11)$ & 9 \\
Amolecida & $15(83)$ & $1(6)$ & $2(11)$ & 18 \\
Dura & $21(64)$ & $12(36)$ & 0 & 33 \\
Total & $42(70)$ & $15(25)$ & $3(5)$ & $60(100)$ \\
\hline
\end{tabular}




\section{DISCUSSÃO}

Visando trabalhos futuros e enfatizando a busca por instrumentos de pesquisa que possam refletir questões subjetivas tais como os hábitos alimentares quanto à sua consistência, torna-se importante iniciar a discussão desse trabalho abordando esse item. Observou-se, e vale ressaltar, que é bastante difícil a elaboração e análise de um instrumento que vise definir o tipo de consistência alimentar a partir de questionamento. Algumas questões mostraram-se pouco decisivas quanto à verificação da consistência alimentar. São elas: comer pão de sal (questão 8) e colocar muito feijão (questão 4). Considerou-se que o caldo do feijão é um líquido que pode amolecer o alimento, porém, observouse durante a aplicação dos questionários que o conceito quantitativo "muito feijão" parece bastante relativo e pessoal, já que dependendo de sua consistência pode não amolecer os alimentos e por isso talvez não configure um hábito facilitador. Quanto ao pão de sal, constatou-se que a grande maioria das crianças o utiliza, provavelmente por tratar-se de alimento básico de grande aceitação em nossa cultura, não sugerindo qualquer dado quanto à consistência.

As demais questões do questionário não mostraram diferenças significativas entre os dois grupos embora, para todas elas, o grupo com apinhamento dentário tenha apresentado maior índice de respostas que sugerem alimentação amolecida.

Os achados do presente trabalho mostraram três questões do questionário com diferenças significativas. São elas: comer carne em bife, dificuldade ou "preguiça" para mastigá-lo e beber líquido durante a refeição na presença do alimento na boca.

Observou-se que a maioria das crianças que não come carne em bife; tipo de alimento considerado de consistência dura ${ }^{23}$; e aquelas que referem "dificuldade ou preguiça para mastigar o bife", apresentam apinhamento dentário. Este resultado está de acordo com estudos que apontam que a falta desses estímulos interfere nas dimensões dos arcos maxilares ${ }^{1,2,4-8}$ e que a mastigação de alimentos duros, como carne fibrosa, possibilita estímulos de crescimento e menores interferências na oclusão ${ }^{1,2,5,6}$, confirmado pela maior porcentagem de crianças sem apinhamento dentário com respostas afirmativas quanto a esse item.

Em relação à questão sobre "beber líquido durante a refeição na presença do alimento na boca", maior número de participantes com apinhamento dentário $(83,33 \%)$ bebe líquido ainda com o alimento na boca, enquanto grande parte $(80 \%)$ das crianças sem apinhamento não apresenta esse hábito. Esse resultado está concordante com estu- dos com animais $7,8,12,14$, que mostraram os grupos alimentados com comida amolecida em água com crescimento reduzido em diversas estruturas craniofaciais, dentre eles os ossos maxilares, concluindo que existe relação entre a consistência alimentar e desenvolvimento da oclusão e que a mudança na consistência alimentar muda a demanda funcional dos músculos mastigatórios, afetando o crescimento ósseo maxilofacial.

A partir da análise dos dados dessa pesquisa pode-se observar que crianças com apinhamento dentário preferem alimentação predominantemente amolecida, enquanto as crianças sem apinhamento dentário parecem ter alimentação predominantemente dura. Esses achados são concordantes com estudos ${ }^{4-6,10}$ salientando que a mastigação de alimentos duros e consistentes seria responsável pelo desenvolvimento das dimensões dos ossos maxilares por estimular o crescimento ósseo evitando apinhamento dentário, enquanto a textura amolecida dos alimentos e a conseqüente diminuição da força mastigatória poderiam levar a alteração anatômica do sistema estomatognático, inclusive da oclusão. Apontam que a mastigação atua no aumento das dimensões dos arcos osteodentários por meio da pressão nos dentes no momento da mastigação e que é transformada em tração sobre o osso, proporcionando assim, crescimento da região alveolar, manutenção dos arcos dentários, e conseqüente estabilidade da oclusão ${ }^{2,3,5}$. Nesse sentido, a alimentação amolecida, característica do regime alimentar da população contemporânea, pode significar fator de perturbação do crescimento, pois se observou que o apinhamento na dentição decídua é mais comum e grave na população contemporânea comparado à população de 50 anos antes ${ }^{4}$. Assim, a crescente incidência do apinhamento dentário nos últimos anos na população de áreas urbanas traz referência à mudança da consistência alimentar nestas regiões ${ }^{19}$.

Os achados são concordantes também com estudos utilizando animais $7,8,12,13$ que mostraram que o consumo preferencial por alimentos amolecidos causa prejuízos ao crescimento do sistema estomatognático, uma vez que a mastigação desses alimentos não favorece estímulos suficientes que favoreçam o crescimento dos ossos maxilares.

Entretanto, estudos mostram que o apinhamento dentário não é apenas decorrente da falta de espaço para a acomodação dos dentes alinhados nos arcos dentários, mas apontam origem multifatorial com muitas variáveis que influem, tais como: maior tamanho dos dentes ${ }^{1}$, características craniofaciais, direção de crescimento mandibular, perda precoce dos dentes decíduos, inclinação dos den- 
tes incisivos e dos molares, assim como a atuação da musculatura oral e perioral ${ }^{1,10,11,19}$.

O apinhamento dentário aparece relatado como a alteração de oclusão mais prevalente na população de diversas localidades ${ }^{4,10,11,17,18}$, sendo citado como desproporção entre o tamanho dos dentes e das arcadas, chamado de discrepância negativa, também devido a fatores hereditários. Diferindo de trabalhos que dizem que apinhamentos dentários eram raros na população pré-histórica, esses foram encontrados nos esqueletos estudados, concluindo que têm origem genética e não são causados apenas por mudanças em fatores ambientais e modificações da função mastigatória ${ }^{9}$.

Os achados do presente estudo não permitem inferir que a consistência alimentar amolecida seja considerada fator etiológico das alterações oclusais caracterizadas por apinhamento dentário, porém apontam para a confirmação de tratar-se de fator contribuinte ou de fazer parte da etiologia multifatorial como proposto por diversos autores $1,4,10,11,26$.

Nesse sentido, pesquisas futuras são necessárias para tentar determinar se o aumento da incidência de apinhamento dentário continuará a ser observado nos diversos tipos de dentição: decídua, mista e permanente; e auxiliar o estabelecimento de possível tendência, associada ou não aos hábitos alimentares.

No estudo da freqüência de ocorrência de alterações na produção da fala em relação à situação do apinhamento dentário presente ou ausente, a pesquisa mostrou a inexistência de relação entre alteração fonológica e alteração oclusal concordando com estudos anteriores ${ }^{21,28}$. Os autores comentam que as alterações fonológicas não são problemas práxicos, mas decorrem de dificuldades no sistema de organização dos sons.

Quanto ao aspecto fonético da produção da fala, observou-se que a maior parte das crianças apresenta fala normal, independente do apinhamento dentário, sendo que o maior número de crianças com fala normal está no grupo de crianças com apinhamento dentário, enquanto maior número de alterações fonéticas aparece no grupo de crianças sem apinhamento dentário.

Esses dados não estão concordantes com os de outros autores ${ }^{20,22,24,25}$ que citaram as distorções na fala, características da alteração fonética, como intrinsecamente relacionados com as alterações na estrutura dentária. Porém, é importante ressaltar que, ao se referirem às más oclusões, esses auto- res citam apenas a classificação de Angle, a sobremordida e a sobressaliência. Em outro estudo ${ }^{29}$, os pesquisadores observaram que a alteração oclusal pode ser um fator de risco para o desenvolvimento da distorção dos fonemas fricativos na fala, embora não seja determinante para sua ocorrência. Outros autores ${ }^{30}$ incluem o apinhamento dentário e referem que as distorções na fala não estão relacionadas com a oclusão, o que vem de encontro com o resultado do presente estudo.

No estudo da comparação da freqüência de alterações na produção da fala em relação à consistência alimentar entre todos os participantes, pode-se perceber que a maior parte das crianças apresenta fala normal, independente do tipo de alimento, e também que o maior índice de alteração fonética está no grupo de crianças com alimentação dura, enquanto o menor índice de alteração fonética encontra-se no grupo de crianças com alimentação amolecida. Esses dados parecem refletir que o tipo de alimentação, quanto à sua consistência, não interfere na produção da fala quanto aos aspectos fonéticos e fonológicos, confirmado por diferenças estatísticas não significativas. Este resultado está em concordância com estudos ${ }^{26,29}$ que apontam que a alimentação de menor consistência não leva a alteração de fala, podendo talvez agravar uma alteração já instalada. Os resultados do presente trabalho não concordam com estudos que pontuam a estimulação da musculatura oral, por meio dos movimentos musculares efetuados na mastigação com adequada consistência alimentar, influindo na articulação fina da fala ${ }^{20}$, e tampouco com aqueles para os quais crianças que fazem uso de alimentação amolecida podem apresentar problemas articulatórios por hipotonia da musculatura facial ${ }^{22}$.

\section{CONCLUSÃO}

A partir dos achados desse estudo pode-se concluir que há indícios de que a presença do apinhamento dentário relaciona-se à consistência alimentar, uma vez que crianças com apinhamento dentário utilizam alimentação amolecida e aquelas sem apinhamento utilizam alimentação dura. A alimentação amolecida parece constituir um dos prováveis fatores etiológicos ou contribuintes à existência do apinhamento dentário. O tipo de alimentação e a presença de apinhamento dentário parecem não interferir na articulação da fala quanto aos aspectos fonéticos e fonológicos. 


\section{ABSTRACT}

Purpose: to characterize the kind of food consistence and speech production in children with normal occlusion and malocclusion related to tooth crowding, as well as to verify possible correlations and interferences. Methods: sixty children from 7 to 12 years old, both genders, divided in two groups: (G1) formed by thirty children with tooth crowding and (G2), the control group, formed by thirty children without tooth crowding. Exclusion criteria: neurological or cognitive problems, oral habits, mouth breathing, dento-facial deformities, orthodontic or speech and language treatment. The procedures were: oral myofunctional and speech evaluation, dentistry evaluation and the appliance of two questionnaires to the children's parents about the child's history and nutrition habits regarding the food consistence. Results: children without tooth crowding usually eat mainly solid food, while those with a crowding arch usually eat softened food, mostly influenced by the habit of drinking while the food is still in the mouth. Conclusion: it seems that tooth crowding is related to food consistence. The soften food consistence seems to be an etiological factor or to contribute to tooth crowding. Food consistence as well as tooth crowding seems not to interfere in speech production.

KEYWORDS: Dental Occlusion; Malocclusion; Child; Speech; Speech Disorders; Articulation Disorders

\section{REFERÊNCIAS}

1. Lindsten R, Ogaard B, Larsson E. Dental arch space and permanent tooth size in the mixed dentition of a skeletal sample from the 14th to the 19th centuries and 3 contemporary samples. Am J Orthod Dentofacial Orthop. 2002; 122(1):48-58.

2. Simões VA. Mastigação e desenvolvimento. In: Simões VA. Ortopedia funcional dos maxilares através da reabilitação neuro oclusal. 3. ed. São Paulo: Artes Médicas; 2003.

3. Bianchini EMG. Mastigação e ATM: avaliação e terapia. In: Machesan IQ, organizador. Fundamentos em fonoaudiologia: aspectos clínicos da motricidade oral. 2. ed. Rio de Janeiro: Guanabara Koogan; 2005. p. 45-58.

4. Warren JJ, Bishara SE, Yonezu T. Tooth sizearch length relationships in the deciduous dentition: a comparison between contemporary and historical samples. Am J Orthod Dentofacial Orthop. 2003; 123(6):614-9.

5. Lefévre AP, Costa NMN, Vieira S. Fonoaudiologia e nutrição: a importância da textura de alimentos. Rev Soc Bras Fonoaudiol. 2000; 5(7):48-53.

6.Duarte LM. Relação entre maloclusão e mastigação. Rev Soc Bras Fonoaudiol. 2001; 6(1):46-51.

7. Ciochon RL, Nisbett RA, Corruccini RS. Dietary consistency and craniofacial development related to masticatory function in minipigs. J Craniofac Genet Dev Biol. 1997; 17(2):96-102.

8. He T, Kiliaridis S. Effects of masticatory muscle function on craniofacial morphology in growing ferrets (Mustela putorius furo). Eur J Oral Sci. 2003; 111(6):510-7.
9. Mockers O, Aubry M, Mafart B. Dental crowding in a prehistoric population. Eur J Orthod. 2004; 26(2):151-6.

10. Türkkahraman $H$, Sayin MO. Relationship between mandibular anterior crowding and lateral dentofacial morphology in the early mixed dentition. Angle Orthod. 2004; 74(6):759-64.

11. Bernabé E, Flores-Mir C. Dental morphology and crowding: a multivariate approach. Angle Orthod. 2006; 76(1):20-5.

12. Ulgen M, Baran S, Kaya $H$, Karadede I. The influence of the masticatory hypofunction on the craniofacial growth and development in rats. Am J Orthod Dentofacial Orthop. 1997; 111(2):189-98.

13. Tokimasa C, Kawata T, Fujita T, Kaku M, Kawasoko S, Kohno S, et al. Effects of insulin-like growth factor-I on nasopremaxillary growth under different masticatory loadings in growing mice. Arch Oral Biol. 2000; 45(10):871-8.

14. Tanigute CC, Saboia-Morais SMT, Souza CB, Souza CP. Comportamento morfológico do músculo masseter de ratos wistar submetidos à dieta pastosa. Rev Cons Fed Fonoaudiol. 2002; 2(2):20-30.

15. Schumacher GH. Regulative and adaptive factors in craniofacial growth. Ann Anat. 1999; 181(1):9-13.

16. Abu Alhaija ES, Qudeimat MA. Occlusion and tooth/arch dimensions in the primary dentition of preschool jordanian children. Int J Paediatr Dent. 2003; 13(4):230-9.

17. Abu Alhaija ES, Al-Khateeb SN, Al-Nimri KS. Prevalence of malocclusion in 13-15 year-old north jordanian school children. Community Dent Health. 2005; 22(4):266-71. 
18. Mugonzibwa EA, Kuijpers-Jagtman AM, Van 't Hof MA, Kikwilu EN. Demand for orthodontic treatment among 9-18 year-olds seeking dental care in Dar-es-Salaam, Tanzania. East Afr Med J. 2004; 81(1):3-9.

19. Silva Filho OG, Ozawa TO, Almeida AM, Freitas PZ. Programa de extrações seriadas: uma visão ortodôntica contemporânea. Rev Dental Press Ortodon Ortop Fac. 2001; 6(2):91-108.

20. Maciel CT, Mogina CM, Leite ICG. Características da dentição decídua: noções para o fonoaudiólogo. J Bras Fonoaudiol. 2002; 3(13):313-7.

21. Pereira MMB, Bianchini EMG, Jardim ZMG. Investigação da ocorrência e caracterização de distorções do [s] em crianças de 3 a 10 anos. Rev Soc Bras Fonoaudiol. 2003; 8(1):10-7.

22. Peña NR, Cerqueira PA, Faria VF. Anomalias da oclusão e transtornos na articulação das palavras. J Bras Fonoaudiol. 2004; 5(21):27-32.

23. Silveira LDBR, Goldenberg M. Hábitos e preferências alimentares de crianças com três a cinco anos de idade. Rev CEFAC. 2001; 3(1):37-44.

24. Carelli E, Sá M. Análise fonética em portadores de alterações dentárias. Fono Atual. 2001; 4(15):39-42.
25. Cunha DA, Sorares MN, Campos E. Como alterações do sistema estomatognático podem comprometer a fonoarticulação. J Bras Fonoaudiol. 2003; 4(15):120-6.

26. Marchesan I. Práticas fonoaudiológicas: uma visão compreensiva. [doutorado]. Campinas (SP): Universidade Estadual de Campinas; 1998.

27. Marchesan IQ. Alterações da fala de origem musculoesqueléticas. In: Ferreira LP, BefiLopes DM, Limongi SCO, organizador. Tratado de fonoaudiologia. 1. ed. São Paulo: Roca; 2004. p. 292-303.

28. Gonçalves CS, et al. Caracterização do perfil clínico de sujeitos com desvios fonéticos e fonológicos: dados preliminares. J Bras Fonoaudiol. 2005; 5(22):304-13.

29. Tomé MC, Farias SR, Araújo SM, Schimitt $E$. Ceceio interdental e alterações oclusais em crianças de 03 a 06 anos. Pró-Fono. 2004; 16(1):19-30.

30. Tomita NE, Bijella VT, Franco LJ. Relação entre hábitos bucais e má oclusão em pré-escolares. Rev Saúde Públ. 2005; 4(1):23-9.

RECEBIDO EM: 18/12/2007

ACEITO EM: 05/03/2008

Endereço para correspondência:

Rua Treze de Maio, 42/502

Barbacena - MG

CEP: 36201-102

Tel: (32) 33315408 / (32) 99441636

E-mail: claudiarpena@gmail.com 